by the name of Volkmannia Binneyi to be the cones of Calamites. On the other hand, whilst I do not deny that such may possibly be their nature, I contend that we have neither proof nor even probable evidence sustaining this idea, Dr. Dawson says that Asterophyllites and Annularia are very distinct plants. Mr. Carruthers affirms that they are not. M. Grand-Eury and myself contend that Asterophyllites is wholly distinct, both in type and organisation, from Calamites. Mr. Carruthers believes that Asterophyllites and Annularia are alike the foliage of Calamites. It would be easy to multiply illustrations proving the existence of these opposite conclusions on important points amongst those observers who have enjoyed the best opportunities of forming reasonable cpinions on such subjects. It is sufficiently obvious that some of us must be in error on these questions ; possibly each of us is so in a greater or less degree ; but when we regard the scientific status of the observers to whom I have referred, leaving myself out of the question, I ask, are they men whom we can accuse lightly of carelessness or ignorance ? Must we not rather infer that each man has observed special facts leading him to his own conclusions, and that what we want is a careful comparison of such facts with those which have led our fellow-labourers in an opposite direction to ourselves? Whatever may be the explanation of these discrepant opinions, surely our mutual duties are clear. If any of us thinks that his fellow-labourer has made mistakes (and who has not) let him say so openly, and not suggest the idea by indulging in deprecatory insinuations. Let his opposing argumentum be $a d$ ren, and not ad hominem. Further, let it be ad rem and not ad alteram rem. Let it not rest upon mere analogies, which may or may not be sound. Let us not reject a conclusion before we know all the facts from which it is drawn, merely because we think we have reason to deem it an impossible one. We have all lived to see many such conclusions take their places as undoubted truths.

One source of danger on these "points, in the case of fossil botany, arises from the circumstance that though the ancient types of vegetation bear definite relations to the living ones, very remarkable differences present themselves in the combinations of the vegetative and reproductive organs in the two cases. Who, for instance, could have anticipated, from his knowledge of living plants, such an union of the usual vegetative organs of a cycad with an altogether anomalous reproductive system as we see in Williamsonia gigas. Many such examples will occur to those familiar with the subject. Hence, whilst a knowledge of living plants is absolutely indispensable to the student of fossil botany,-he cannot have too much of it--we must not allow our knowledge of recent combinations of vegetative and reproductive structures unduly to bias our judgment as to what may occur amongst fossil plants. Whilst we fully recognise the persistence of types, we must equally recognise the wonderful modifications which they have undergone in primæval times.

The conclusions to which these views lead me are very simple ones. The complex problems of palxophytology require harmonious and trustful co-operation amongst observers if truth is to be discovered. Let us supply this in the spirit of cordial fellow-labourers, and not as rivals in pursuit of a fleeting reputation which cannot be shared with others. We shall never raise ourselves by pulling others down. I will not quote the special expressions that are present to my mind whilst penning these lines; but it would be easy to do so, and to show that no possible benefits can accrue to science from their use. We can easily correct our mutual errors, we cannot so easily sooth wounded feelings, or restore shaken confidences. We aim at being the high priests of nature ; let us try to banish all disturbing personal and selfish influences from the temple.

These words of warning may appear superfluous; be- cause they embody mere truisms, equally applicable to every branch of human inquiry, or impertinent, seeing that in the fervour of earnest work, I may have erred in the same way as my neighbours. The fact is, that, like others of my earlier fellow-workers, I am rapidly approaching the autumn of life, and peace and harmony now appear more precious to me than they did in bygone years, when youthful ambition was alike active and inconsiderate. Happily ours are not pursuits which require us to cry va victis! Just in proportion as we meet our opponents in a loving and harmonious spirit, without abandoning, in any degree, our earnest contention for what we believe to be truth, shall we, in our declining years, review our past labours with satisfaction and not with sorrow.-Sic esto.

W. C. Williamson

\section{DISTRIBUTION OF HEAT IN THE} SPECTRUM

PROF. J. W. DRAPER has communicated to Silliman's Fournal of Science and Art for September a very important article under the above heading. After detailing a series of experiments on the distribution of the heat of the whole visible spectrum, of the more refrangible and of the less refrangible region, by rock-salt, flint-glass, bisulphide of carbon, and quartz, he thus sums up the results :-

"The important fact clearly brought into view by these experiments is, that if the visible spectrum be divided into two equal portions, the ray having a wave-length of 5768 being considered as the optical centre of such a spectrum, these portions will present heating powers so nearly equal that we may impute the differences to errors of experimentation. Assuming this as true, it necessarily follows that in the spectrum any two series of undulations will have the same heating power, no matter what their wave-lengths may be.

"But this conclusion leads unavoidably to a most important modification of the views now universally held as regards the constitution of the spectrum. When a ray falls on an extinguishing surface heat is produced, but that heat did not pre-exist in the ray. It arose from the stoppage of ether waves, and is a pure instance of the conversion of motion into heat-an illustration of the modern doctrines of the conservation and transmutation of force.

"From this point of view the conception that there exist in an incident ray various principles disappears altogether. We have to consider an incident ray as consisting solely of etherial vibrations, which, when they are checked by an extinguishing substance, lose their vis viva. The effect that ensues depends on the quality of the substance. The vibrations imparted to it may be manifested by the production of heat, as in the case of lamp-black, or by chemical changes, as in the case of many of the salts of silver. In the parallel instance of acoustics clear views have long ago been attained, and are firmly held. No one supposes that sound is one of the ingredients of the atmosphere, and it would not be more incorrect to assert that it is something emitted by the sounding body than it is to affirm that light or heat, or actinism, are emitted by the sun.

"The progress of actino-chemistry would be greatly accelerated if there could be steadfastly maintained a clear conception of the distinction between the mechanism of a ray and the effects to which that ray may give rise. The evolution of heat, the sensation of light, the production of chemical changes, are merely effects-manifestations of the motions imparted to ponderable atomsand these in their turn can give rise to converse results, as when we gradually raise the temperature of a substance the oscillating movements of its molecules are imparted to the ether, and waves of less and less length are successively engendered," 